\title{
THE DISTRIBUTION OF PHOSPHORUS AND GOLD IN NEUTRON IRRADIATED SILICON
}

\author{
F. BÉNIÈRE and V. K. AGRAWAL $\left({ }^{*}\right)$ \\ Laboratoire de Physique des Matériaux, Institut Universitaire de Technologie, \\ 22302 Lannion, France
}

(Reçu le 25 avril 1978, accepté le 23 juin 1978)

\begin{abstract}
Résumé. - L'homogénéité de la concentration de phosphore crée par transmutation nucléaire ainsi que la distribution d'autres éléments tels que l'or ont été étudiées dans le but d'examiner l'influence à l'échelle microscopique du flux de neutrons dans du silicium irradié aux neutrons. Deux techniques ont été utilisées : i) sectionnement électrochimique et ii) sectionnement mécanique. Les deux méthodes montrent que la concentration de phosphore est uniforme. L'or, au contraire, est concentré à la surface.
\end{abstract}

\begin{abstract}
The uniformity of phosphorus concentration produced by nuclear transmutation and the distribution of other elements such as gold have been studied to observe the possible influence of the neutron flux at a microscopic level in neutron irradiated silicon. Two techniques were used : i) electrochemical sectioning and ii) mechanical sectioning. Both methods show that the phosphorus concentration is uniform throughout. Gold, on the other hand, is concentrated at the surface.
\end{abstract}

1. Introduction. - The doping of silicon by phosphorus by nuclear transmutation using the following reaction :

$$
{ }_{14}^{30} \mathrm{Si}+\mathrm{n} \rightarrow{ }_{14}^{31} \mathrm{Si} \rightarrow{ }_{15}^{31} \mathrm{P}+\beta^{-}
$$

is utilized increasingly [1-5]. The two chief advantages are the ultimate control on the desired donor doping level and the uniformity of doping [1, 3]. In the present paper, the uniformity of distribution of the phosphorus atoms created by nuclear transmutation has been studied on a microscopic scale $(50 \mathrm{~nm}-1000 \mathrm{~nm})$ not investigated before. Further, the distribution of the other elements present in silicon has been studied after irradiation, on the same microscopic scale. In particular, gold added as a lifetime killer in order to decrease the switching time of the device [6] has been carefully investigated.

2. Experimental. - The irradiation of highly pure silicon by neutrons has two roles both of which are used in this paper. The first one is doping by nuclear transmutation. The second one is neutron activation

(*) Permanent address : Physics Department, University of Allahabad, Allahabad 211 002, India. of silicon and background impurities. The measurement of beta-activity of Si-31 gives the number of phosphorus atoms, while the gamma-activity of the activated impurities identifies them and gives their concentration.

2.1 SAMPLES USED. - We have used hyper pure silicon crystals supplied by Wacker. They are floatzone, dislocation free, grown in the 1-0-0 orientation. All the samples considered here are p-type, boron doped, the concentration of boron ranging from $10^{13}$ upto $10^{16} / \mathrm{cm}^{3}$. Our activation analysis confirms the high purity if one excepts the gold as will be discussed later.

2.2 IrRadiation. - The silicon wafers are normally irradiated in a thermal neutron flux $J=3.5 \times 10^{13}$ neutrons $/ \mathrm{cm}^{2} / \mathrm{s}$ for the time $t_{1}=24$ hours.

From the specific activity due to the emitted beta-rays which corresponds to the half-life time of Si-31 $(2.62 \mathrm{~h})$ the neutron cross-section is found to be $\sigma=0.12$ barn from the equation [7] :

$$
\begin{aligned}
& A=36 \times \frac{\sigma \times J}{M} \times \frac{1-\exp \left(-\lambda t_{1}\right)}{\exp \left(\lambda t_{2}\right)} \times \\
& \times R C \times A I \times P M
\end{aligned}
$$


where $A$ is the specific activity in counts per minute and per gram of silicon $(M=28.1)$, at the time $t_{2}$ after removal from the pile. The efficiency of our low background (1 cpm) Geiger counter is $R C=0.30$ for this electron energy, the isotopic abundance of $\mathrm{Si}-30$ is $A I=0.030$, the fraction of mode of decay is $P M=1$ and $\lambda$ is the radioactive constant of Si-31.

For irradiation times of one day or more, the activity of $\mathrm{Si}-31$ attains its saturation value. The concentration $C$ of $\mathrm{P}-31$ atoms expressed as the number of atoms per $\mathrm{cm}^{3}$ of silicon is then derived from the following equation :

$$
C=A \times \exp \left(\lambda t_{2}\right) \times \rho \times t_{1}
$$

where $\rho$ is the specific mass of silicon.

2. 3 Electrochemical SECTIONing. - Samples of dimensions $12 \mathrm{~mm} \times 12 \mathrm{~mm}$ are cut from the wafers and mounted in an electrochemical cell. Sectioning of the crystals is done by successively oxidizing and removing layers of silicon parallel to the flat surface of the wafer using the anodic oxidation technique. Thickness of each section is determined by weighing the crystal with a microbalance immediately before and after oxidation. The average thickness can be varied up to $100 \mathrm{~nm}$ with the present apparatus. The beta rays emitted by $\mathrm{Si}-31$ are counted for each section removed with an anti-coincidence beta counter. Equation (2) is again used to derive the concentration of the phosphorus atoms (per $\mathrm{cm}^{3}$ of $\mathrm{Si}$ ) from the specific activity.

2.4 Mechanical Sectioning. - Strips of width $5 \mathrm{~mm}$ are cut from the wafers and then sectioned with a microtome into $3 \mu \mathrm{m}$ slices perpendicular to the original flat surface of the wafer according to the technique developed earlier [7].

The radioactivity is measured in each slice using a beta counter for determining the concentration of phosphorus as well as a gamma counter for determining the concentration of the elements activated in the process, especially gold.

3. Results. - 3.1 Distribution OF PHOSPhORUS. - The concentration of the phosphorus atoms calculated from the activity of $\mathrm{Si}-31$ in an anodic oxidation experiment is shown on figure 1 . We accumulate the countings, for typically 10 minutes, to get a total number of 2000 counts per slice. The background being only $1 \mathrm{cpm}$, the error of counting is the statistical error only, namely $1 / \sqrt{2000} \simeq 0.02$. The thickness removed in each anodic oxidation as measured from the difference in weight of the sample with a microbalance is equal to $(60 \pm 10) \mathrm{nm}$. The error on the thickness is thus $16 \%$, this gives a total error of $18 \%$. The standard mean deviation (Fig. 1) is slightly less than $10^{14}$ atoms $/ \mathrm{cm}^{3}$, so that the mean fluctuation of the data points is equal to

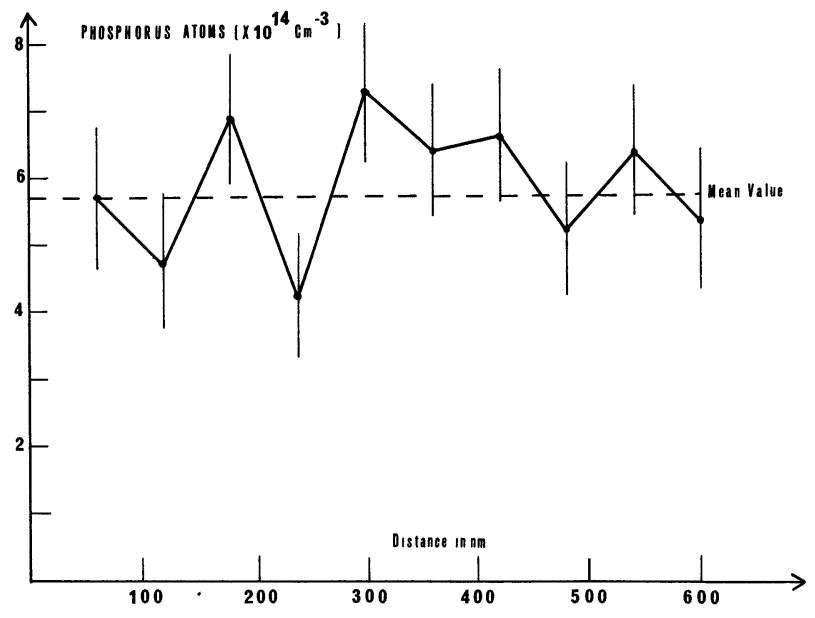

Fig. 1. - Concentration of phosphorus in successive layers of silicon sectioned by anodic oxidation parallel to the main surface.

$15 \%$. We can then conclude the uniformity of phosphorus distribution within the limits of error. The point to be emphasized is that the uniformity already demonstrated at the macroscopic scale is found in the present work at the microscopic scale of $60 \mathrm{~nm}$.

However, as the reproducibility of the thickness of the anodic sections is not excellent and as the time for anodic oxidation is too long compared with the limited time available with $\mathrm{Si}-31$, microtome sectioning is found to provide a better way for investigating the uniformity of $\mathrm{P}$ in $\mathrm{Si}$. As a matter of fact, it is possible with a single irradiation to measure the concentration of $P$ in 400 sections of preset thickness ranging from 1 to $10 \mu \mathrm{m}$ with a very good reproducibility of thickness. The results plotted on figure 2 again show the uniformity of phosphorus distribution within the experimental errors of measurement which is much less for this mechanical sectioning $(5 \%)$.

In all the samples which have been studied, about $50 \%$ of the data points lie within $\pm 5 \%$ of the average concentration.

In preliminary experiments some sections exhibited more beta activity. This was resolved as due to impurities present at the surface of the crystal which were activated during irradiation. All the impurities were easily removed by washing the crystal in $5 \% \mathrm{HF}+5 \% \mathrm{HNO}_{3}$ solution except for gold which is present in the whole bulk.

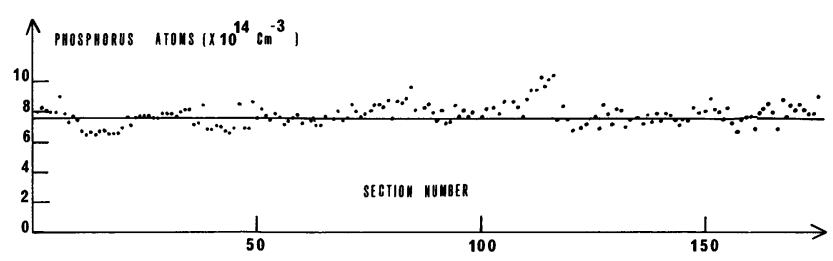

FIG. 2. - Concentration of phosphorus in successive layers of silicon sectioned by microtoming perpendicular to the main surface. The activity of Si-31 has been separated from Au-198 activity and corrected for the radioactive decay. 
3.2 Distribution of GOLD. - About 4 days after removal from the pile, when $\mathrm{Si}-31$ has completely decayed (Fig. 3), p-type (boron doped) silicon samples were sectioned using anodic oxidation in order to determine the concentration of gold. The gamma

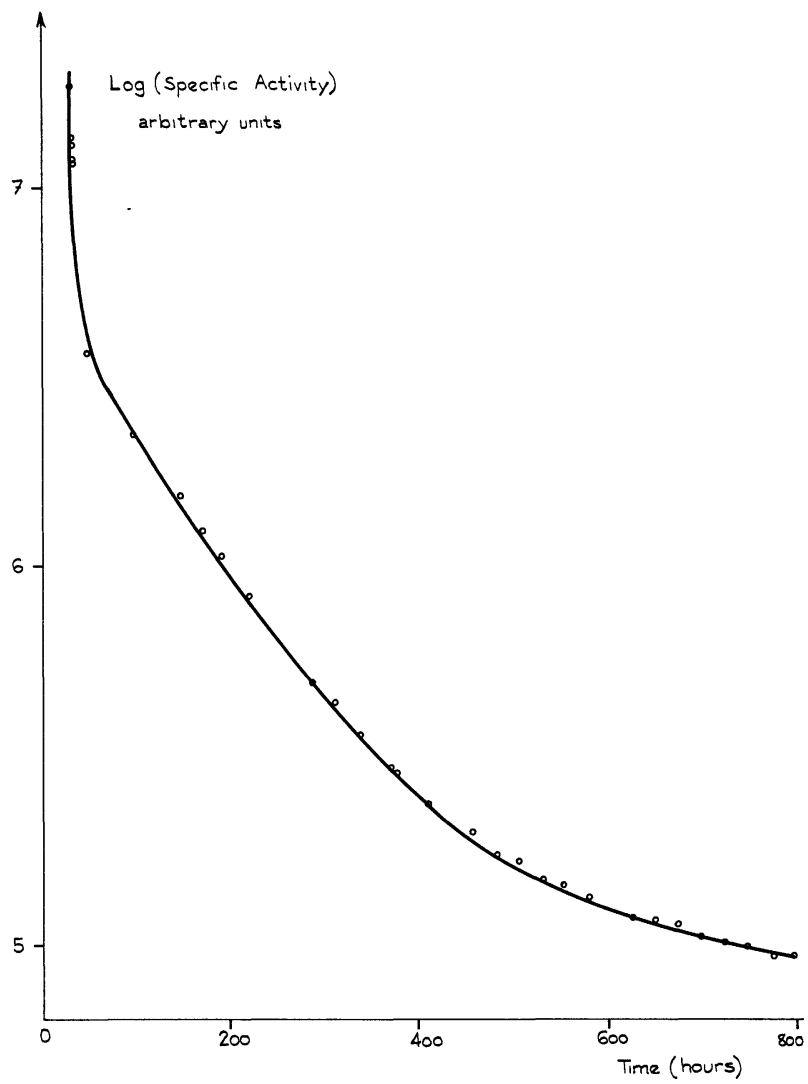

FIG. 3. - Decay curve of a radioactive section as a function of time.

energy spectrum taken at that time (Fig. 4) of a removed section shows the $0.4 \mathrm{MeV}$ peak of Au-198. The gamma energy spectrometer was adjusted on this peak, to determine the concentration of gold in each section of $90 \mathrm{~nm}$ thick. Figure 5 shows the concentration of gold atoms per $\mathrm{cm}^{3}$ as a function

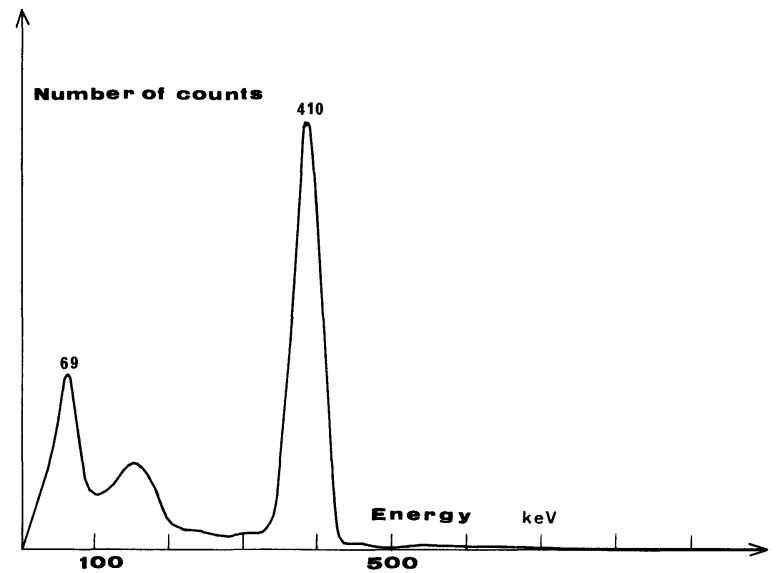

FIG. 4. - Gamma energy spectrum of a section showing all the peaks of Au-198.

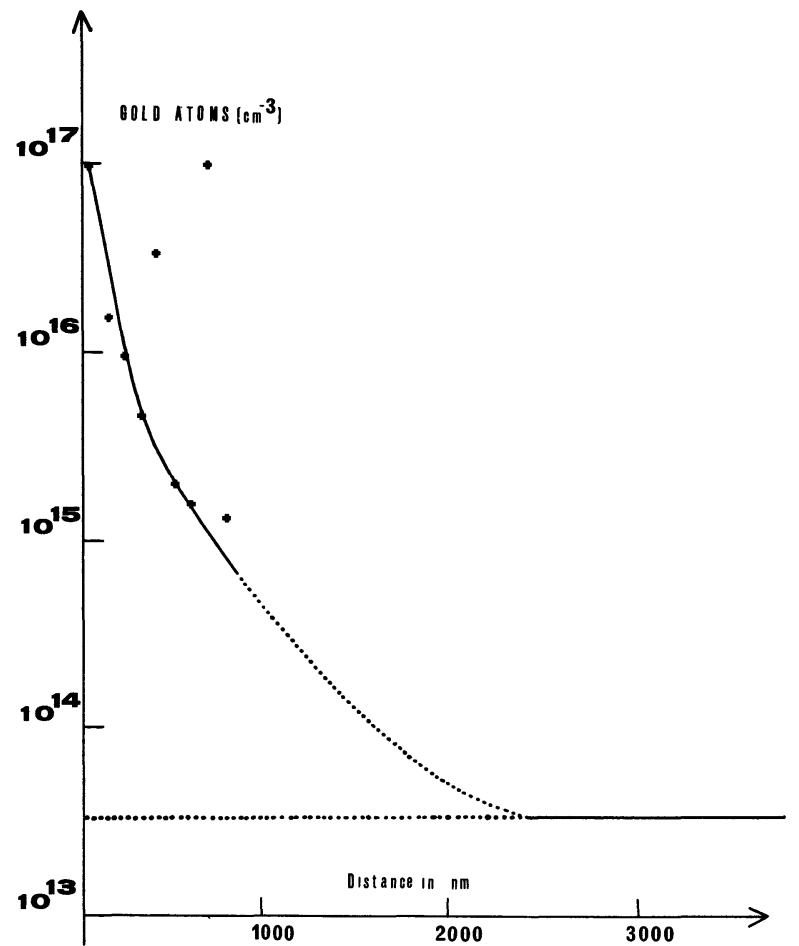

Fig. 5. - Content of gold atoms in successive layers of silicon obtained by anodic oxidation (thickness of each section : $90 \mathrm{~nm}$ ).

of depth ; it drastically decreases from $10^{17} \mathrm{~cm}^{-3}$ in the first section down to $10^{15} \mathrm{~cm}^{-3}$ at $1 \mu \mathrm{m}$ to finally drop to the value of $3 \times 10^{13} \mathrm{~cm}^{-3}$ in the bulk of the crystal. This profile is typical of gold [8]. This distribution may already be present during the preparation of the wafers, or due to an outward diffusion during the irradiation or the subsequent annealing (one hour at $500{ }^{\circ} \mathrm{C}$ ) necessary for obtaining conductive samples for the anodic oxidation.

Lastly, it was noticed that two sections were more active than their neighbours. It was often found that one section out of about ten contains an anomalously high gold content. The origin of this is not as yet clear.

4. Conclusions. $-a$ ) The phosphorus produced by nuclear transmutation is distributed uniformly in the crystal. Such a conclusion had already been drawn from macroscopic electrical measurements [1]. This conclusion is confirmed on a microscopic scale down to $50 \mathrm{~nm}$. In particular, no aggregation of the created atoms has been observed on this scale.

b) In those samples in which gold atoms have deliberately been added a rapid decrease of three orders of magnitude is found between the concentration at the very surface and in the bulk. This decrease occurs over a few microns.

Acknowledgments. - One of us (V.K.A.) is thankful to the French Foreign Office for the award of a Visiting Fellowship. 


\section{References}

[1] HaAs, E. W. and Schnoller, M. S., J. Electron. Mater. 5 (1976) 57 ; IEEE Trans. Electron Devices 23 (1976) 803.

[2] Krull, W. and Martens, P., Kerntechnik 19 (1977) 131.

[3] Yusa, A., Yatsurugi, Y. and Takaishi, T., J. Electrochem. Soc. 124 (1977) 312.

[4] Tanenbaum, M. and Mills, A. D., J. Electrochem. Soc. 108 (1961) 171.
[5] Braggins, T. T., Hobgood, H. M., TakeI, W. J. and Thomas, R. N., IEEE Trans. Electron Devices 24 (1977) 1195. [6] Brotherton, S. D. and Rogers, T. L., Solid State Electron. 15 (1972) 853.

[7] Bénière, F., Rev. Phys. Appl. 12 (1977) 1805.

[8] Boltaks, B., Diffusion et défauts ponctuels dans les semi-conducteurs (Traduction française, Editions Mir), 1977. 